\title{
Kinetic Analysis of Ethyl Iodide Pyrolysis Based on Shock Tube Measurements
}

\author{
TAMÁS VARGA, ${ }^{1,2}$ ISTVÁN GY. ZSÉLY, ${ }^{1}$ TAMÁS TURÁNYI, ${ }^{1}$ \\ TOBIAS BENTZ, ${ }^{3}$ MATTHIAS OLZMANN ${ }^{3}$ \\ ${ }^{1}$ Institute of Chemistry, Eötvös University (ELTE), Budapest, Hungary \\ 2 MTA-ELTE Research Group on Complex Chemical Systems, Budapest, Hungary \\ ${ }^{3}$ Institute of Physical Chemistry, Karlsruhe Institute of Technology, Karlsruhe, Germany
}

Received 31 May 2013; revised 18 August 2013; accepted 8 September 2013

DOI 10.1002/kin.20829

Published online 28 October 2013 in Wiley Online Library (wileyonlinelibrary.com).

\begin{abstract}
The optimization of a kinetic mechanism of the pyrolysis of ethyl iodide was carried out based on data obtained from reflected shock wave experiments with H-ARAS and I-ARAS detection. The analysis took into account also the measurements of Michael et al. (Chem. Phys. Lett. 2000, 319, 99-106) and Vasileiadis and Benson (Int. J. Chem. Kinet. 1997, 29, 915925) of the reaction $\mathrm{H}_{2}+\mathrm{I}=\mathrm{H}+\mathrm{HI}$. The following Arrhenius parameters were determined for the temperature range $950-1400 \mathrm{~K}$ and the pressure range $1-2$ bar: $\mathrm{C}_{2} \mathrm{H}_{5} \mathrm{I} \rightarrow \mathrm{C}_{2} \mathrm{H}_{5}+$ $\mathrm{I}: \log _{10}(\mathrm{~A})=13.53, \mathrm{E} / \mathrm{R}=24,472 \mathrm{~K} ; \mathrm{C}_{2} \mathrm{H}_{5} \mathrm{I} \rightarrow \mathrm{C}_{2} \mathrm{H}_{4}+\mathrm{HI}: \log _{10}(\mathrm{~A})=13.67, \mathrm{E} / \mathrm{R}=27,168$ $\mathrm{K} ; \mathrm{H}+\mathrm{HI} \rightarrow \mathrm{H}_{2}+\mathrm{I}: \log _{10}(\mathrm{~A})=13.82, \mathrm{E} / \mathrm{R}=491 \mathrm{~K} ; \mathrm{C}_{2} \mathrm{H}_{5} \mathrm{I}+\mathrm{H} \rightarrow \mathrm{C}_{2} \mathrm{H}_{5}+\mathrm{HI}: \log _{10}(\mathrm{~A})$ $=15.00, \mathrm{E} / \mathrm{R}=2593 \mathrm{~K}$ (the units of $\mathrm{A}$ are $\mathrm{cm}^{3}, \mathrm{~mol}, \mathrm{~s}$ ). The joint covariance matrix of the optimized Arrhenius parameters was also determined. This covariance matrix was converted to the temperature-dependent uncertainty parameters $f$ of the rate coefficients and also to the temperature-dependent correlation coefficients between pairs of rate coefficients. Each fitted rate coefficient was determined with much lower uncertainty compared to the estimated uncertainty of the data available in the literature. (c) 2013 Wiley Periodicals, Inc. Int J Chem Kinet 46: 295-304, 2014
\end{abstract}

\section{INTRODUCTION}

Ethyl iodide is widely used as a precursor for hydrogen atoms in shock tube experiments, and applications have been reviewed in a previous publication [1]. For typical experiments with detection by atomic resonance absorption (initial concentrations $<5 \mathrm{ppm}$ and time

Correspondence to: Tamás Turányi; e-mail: turanyi@chem .elte.hu.

Supporting Information is available in the online issue at www.wileyonlinelibrary.com.

(C) 2013 Wiley Periodicals, Inc. resolution $>10 \mu \mathrm{s}$ ), it is usually assumed that $\mathrm{C}_{2} \mathrm{H}_{5} \mathrm{I}$ decomposes instantaneously when the applied temperature is higher than $1200 \mathrm{~K}$. However, in experiments with short observation times and high time resolution the decomposition of $\mathrm{C}_{2} \mathrm{H}_{5} \mathrm{I}$ can be temporally resolved even at much higher temperatures. In general, however, it is necessary to model the decomposition of $\mathrm{C}_{2} \mathrm{H}_{5} \mathrm{I}$ at temperatures lower than $1200 \mathrm{~K}$ to accurately account for secondary reactions as the precursor is consumed. This means that at some experimental conditions, the bimolecular reactions that follow the $\mathrm{C}_{2} \mathrm{H}_{5} \mathrm{I}$ decomposition are no longer negligible. In this case, the reaction mechanism used for the interpretation of the shock tube 
Table I Initial Reaction Mechanism and Kinetic Data Taken from [1] and the Optimized Arrhenius Parameters

\begin{tabular}{lcrrr}
\hline & \multicolumn{2}{c}{ Initial Model } & \multicolumn{2}{c}{ Optimized Model } \\
\cline { 2 - 3 } & $\log _{10}(A)$ & $E / R$ & $\log _{10}(A)$ & $E / R$ \\
\hline $\mathrm{R} 1: \mathrm{C}_{2} \mathrm{H}_{5} \mathrm{I} \rightarrow \mathrm{C}_{2} \mathrm{H}_{5}+\mathrm{I}$ & 13.00 & 23,200 & 13.53 & 24,472 \\
$\mathrm{R} 2: \mathrm{C}_{2} \mathrm{H}_{5}+\mathrm{M} \rightarrow \mathrm{C}_{2} \mathrm{H}_{4}+\mathrm{H}+\mathrm{M}$ & 18.00 & 16,800 & 18.00 & 16,800 \\
$\mathrm{R} 3: \mathrm{C}_{2} \mathrm{H}_{5} \mathrm{I} \rightarrow \mathrm{C}_{2} \mathrm{H}_{4}+\mathrm{HI}$ & 13.23 & 26,680 & 13.67 & 27,168 \\
$\mathrm{R} 4: \mathrm{H}+\mathrm{HI} \rightarrow \mathrm{H}_{2}+\mathrm{I}$ & 13.68 & 330 & 13.82 & 491 \\
$\mathrm{R} 5: \mathrm{C}_{2} \mathrm{H}_{5} \mathrm{I}+\mathrm{H} \rightarrow \mathrm{C}_{2} \mathrm{H}_{5}+\mathrm{HI}$ & 15.62 & 3,940 & 15.00 & 2,593 \\
\hline
\end{tabular}

Arrhenius parameters of reaction (R2) were not changed during the optimization. The units are mol, $\mathrm{cm}^{3}, \mathrm{~s}, \mathrm{~K}$.

experiments has to be extended with the submechanism for the ethyl iodide pyrolysis.

In the present work, the rate parameters of the ethyl iodide thermal decomposition mechanism were determined by fitting the Arrhenius parameters to shock tube experimental data. The method applied for the determination of the rate parameters for the reaction mechanism, by fitting several rate parameters simultaneously to a large amount of experimental data, has been described in our previous publications $[2,3]$.

\section{SHOCK TUBE EXPERIMENTAL DATA AND THE INITIAL REACTION MECHANISM}

The experiments were conducted in a stainless steel shock tube behind reflected shock waves at temperatures between 957 and $1397 \mathrm{~K}$ and pressures between 1.3 and 1.8 bar with argon as bath gas. Since our experimental approach has been described in more detail elsewhere [1], only a brief outline is given here. The initial concentration of $\mathrm{C}_{2} \mathrm{H}_{5} \mathrm{I}$ was in the range (2.16.6) $\times 10^{13} \mathrm{~cm}^{-3}$, and a summary of the experimental conditions is presented in Table 1 of the Supporting Information. The thermal decomposition reaction behind the reflected shock wave was monitored using ARAS (atom resonance absorption spectroscopy): H-ARAS (in 23 cases) and I-ARAS (in six cases) at wavelengths of 121.6 and $183 \mathrm{~nm}$, respectively. In each experiment, the hydrogen and iodine atom concentration profiles consisted of about 4500 data points. The concentration of the hydrogen atom was calibrated with the wellknown $\mathrm{N}_{2} \mathrm{O} / \mathrm{H}_{2}$ reaction system [4-6], and the iodine atom concentration was calibrated by means of the thermal decomposition of $\mathrm{CH}_{3} \mathrm{I}[1,7]$.

In [1] the following reaction mechanism was used for the interpretation of the experimental data:

$$
\begin{gathered}
\mathrm{C}_{2} \mathrm{H}_{5} \mathrm{I} \rightarrow \mathrm{C}_{2} \mathrm{H}_{5}+\mathrm{I} \\
\mathrm{C}_{2} \mathrm{H}_{5}+\mathrm{M} \rightarrow \mathrm{C}_{2} \mathrm{H}_{4}+\mathrm{H}+\mathrm{M}
\end{gathered}
$$

$$
\begin{gathered}
\mathrm{C}_{2} \mathrm{H}_{5} \mathrm{I} \rightarrow \mathrm{C}_{2} \mathrm{H}_{4}+\mathrm{HI} \\
\mathrm{H}+\mathrm{HI} \rightarrow \mathrm{H}_{2}+\mathrm{I} \\
\mathrm{C}_{2} \mathrm{H}_{5} \mathrm{I}+\mathrm{H} \rightarrow \mathrm{C}_{2} \mathrm{H}_{5}+\mathrm{HI}
\end{gathered}
$$

Under our conditions, the rate coefficients of the ethyl iodide decomposition reactions are likely to be close to their high-pressure limits, and no significant pressure dependence at pressures between 1.3 and 4.4 bar was found in our earlier experimental study [1]. All experiments considered here were carried out in the pressure range of 1.3-1.8 bar, and no influence of pressure is expected in such a small range. Accounting for pressure dependences is beyond the scope of the present work.

Since reaction (R2) is much faster than reaction (R1), the rate coefficient of reaction (R1) can be determined from the initial rise of the $\mathrm{H}$ atom concentrations obtained from the H-ARAS measurements at the corresponding temperatures. In [1], these values were fitted with a two-parameter Arrhenius expression in the temperature range 950-1130 K. Arrhenius expressions for reactions (R3) and (R5) were obtained from transition state theory calculations. Finally, the Arrhenius parameters for reactions (R2) and (R4) were acquired from the data evaluations [8] and [9], respectively.

The model suggested in [1] reproduced the ARAS measurements basically right; therefore, the above mechanism (also listed in Table I) was used as the initial model of the parameter optimization. The experimental data were evaluated using our previously published methods [2,3]. Using this approach, not only the $\mathrm{H}-$ ARAS but also the I-ARAS measurements could be utilized. Also, much more mechanistic information could be obtained from the same set of experimental data.

\section{SELECTION OF PARAMETERS FOR OPTIMIZATION}

The experimental conditions and the results of the shock tube experiments were encoded in PrIMe 
format [10] XML files, and these input files were utilized by our programs. Selection of the rate parameters for optimization was based on local sensitivity analysis of the initial model. The normalized sensitivity coefficients for the simulated $\mathrm{H}$-atom or I-atom concentration-time profiles were calculated at the experimental conditions with respect to Arrhenius parameter $A$ of each reaction step. Reaction steps (R1) and (R3)-(R5) had highly sensitive $A$ factors at several different experimental conditions. Note that reaction (R2) also showed high sensitivity in certain short-time intervals at some experimental conditions, but trial fittings indicated that the Arrhenius parameters of this reaction cannot be determined from the current set of experimental data. The temperature dependence of the corresponding rate coefficients was described with $\mathrm{Ar}-$ rhenius parameters $A$ and $E$; therefore, these eight $(4 \times$ 2) Arrhenius parameters were fitted to the experimental data.

\section{UTILIZING EXTERNAL MEASUREMENTS OF THE RATE COEFFICIENTS}

The data-processing algorithm as described in [2] and [3] includes that the results of indirect measurements (like $\mathrm{H}$ and I atom concentration profiles in this case) can be used together with the results of measurements for the determination of the rate coefficients from the literature. A comprehensive literature search was carried out for the measured rate coefficients of the four selected reactions. For reactions (R1), (R3), and (R5), the rate coefficients found were determined at very different temperatures. For reaction (R4), Michael et al. [11] measured the rate coefficient of the reverse $\left(\mathrm{H}_{2}+\mathrm{I} \rightarrow \mathrm{H}+\mathrm{HI}\right)$ reaction in the temperature range of 1755-2605 K using shock tube with I-ARAS detection. The 13 measured rate coefficient values were converted to the forward rate coefficients using the program MECHMOD [12] based on the thermodynamic data. Vasileiadis and Benson [13] measured the rate coefficient of reaction (R4) at $298 \mathrm{~K}$ using a very-lowpressure reactor technique and mass spectrometric detection. These rate coefficients were also handled as experimental data during the optimization.

\section{RANGE OF UNCERTAINTY OF THE ARRHENIUS PARAMETERS TO BE FITTED}

An important step of the optimization procedure is the a priori determination of the temperature-dependent uncertainty limits of the rate coefficients. The uncertainty of the rate coefficient in a range of temperature deter- mines the allowed values of the Arrhenius parameters. For several rate coefficients, many experimental data are available in the literature and therefore the probability density function $(p d f)$ of the rate coefficient can be estimated. This $p d f$ for the rate coefficient at several temperatures determines the $p d f$ of the Arrhenius parameters, thus defining the allowed region of Arrhenius parameters [14].

Knowing the range of uncertainty of the rate parameters is needed for two reasons: If an optimization procedure predicts rate parameters outside the physically realistic domain, then the initial mechanism is not complete, the experimental data are faulty, or the optimization method was not used properly. Also, our optimization procedure uses a global optimization method and it searches the global optimum within the assumed domain of uncertainty of the parameters.

Of the four reaction steps investigated, it was only the rate coefficient of reaction (R4) for which several experimental determinations were carried out near the temperature range of our shock tube experiments, and, therefore, the statistical method [14] for the determination of the domain of uncertainty of the Arrhenius parameters could be used for this reaction only. The corresponding measured rate coefficients were collected from the NIST Chemical Kinetics Database [15]. In the temperature range 700-1000 K, the upper and lower limiting rate coefficient values (denoted by $k^{\text {upper }}$ and $k^{\text {lower }}$, respectively) were determined. The rate coefficient published by Bentz et al. [1] was selected as the temperature-dependent mean rate coefficient value $k^{0}(T)$, and the limiting values were chosen symmetrically around it in such a way that they included the results of Baulch et al. [9], Lorenz et al. [16], and Sullivan [17]. This allowed the calculation of the temperature-dependent uncertainty parameter values $f(T)$ using the following equation:

$$
\begin{aligned}
f(T)= & \max \left(\log _{10} k^{\text {upper }}(T)-\log _{10} k^{0}(T),\right. \\
& \left.\log _{10} k^{0}(T)-\log _{10} k^{\operatorname{lower}^{\prime}}(T)\right)
\end{aligned}
$$

where $k^{0}(T)$ is the rate coefficient at temperature $T$ as used in the initial mechanism. The $f(T)$ points were determined at several temperatures, and the elements of the a priori covariance matrix of the Arrhenius parameters were fitted to these points using the algorithm of Nagy and Turányi [14]. The results are presented in Fig. 1. The $f(T)$ values in the temperature range of the measurements (950-1400 K) were calculated from the fitted a priori covariance matrix.

For reactions (R1), (R3), and (R5), not enough experimental data were available to handle the rate coefficients in a statistical manner. For these reactions, a 


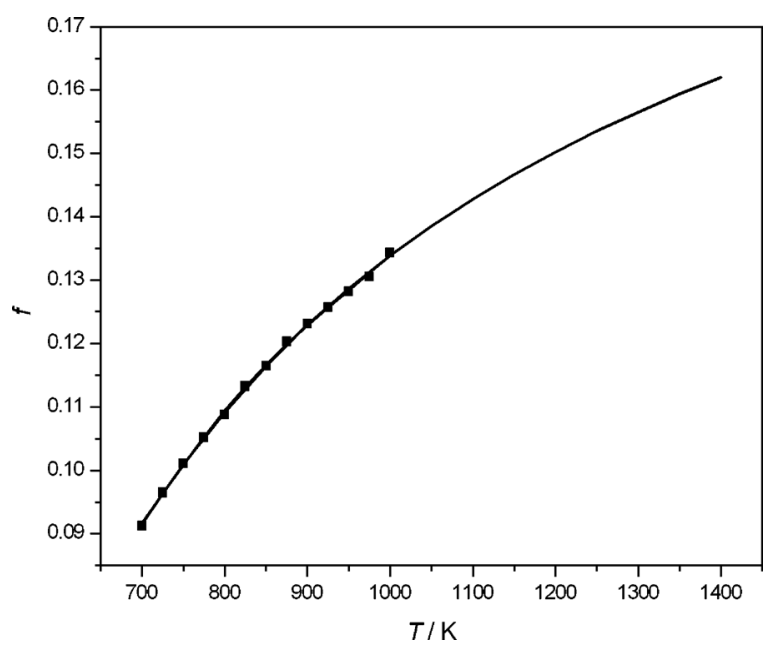

Figure $1 f(T)$ points determined based on the available literature data. The $f(T)$ function is calculated from the fitted elements of the a priori covariance matrix for the reaction $\mathrm{H}+\mathrm{HI} \rightarrow \mathrm{H}_{2}+\mathrm{I}(\mathrm{R} 4)$.

temperature independent uncertainty parameter $f=0.5$ was selected, which means that the rate coefficient was considered to be uncertain within one order of magnitude around the value used in the initial mechanism. This uncertainty range of the rate coefficients defines the range of acceptable Arrhenius parameters.

\section{MECHANISM OPTIMIZATION}

The details of the mechanism optimization procedure have been described in our previous publications [2, $3]$, and a brief summary is given here. The following objective function was used:

$$
\begin{aligned}
E(\mathbf{p}) & =\sum_{\mathrm{i}=1}^{N} E_{\mathrm{i}}(\mathbf{p}) \\
& =\sum_{\mathrm{i}=1}^{N} \frac{1}{N} \frac{w_{i}}{N_{i}} \sum_{j=1}^{N_{\mathrm{i}}}\left(\frac{Y_{i j}^{\bmod }(\mathbf{p})-Y_{i j}^{\exp }}{\sigma\left(Y_{i j}^{\exp }\right)}\right)^{2}
\end{aligned}
$$

where

$$
Y_{i j}=\left\{\begin{array}{c}
y_{i j} \quad \text { if } \sigma\left(y_{i j}^{\exp }\right) \approx \text { constant } \\
\ln y_{i j} \text { if } \sigma\left(\ln y_{i j}\right) \approx \text { constant }
\end{array}\right.
$$

The parameter vector $\mathbf{p}$ includes the Arrhenius parameters of the selected reactions. Experimental result $y_{i j}^{\exp }$ may be a measured concentration or a published rate coefficient $k$ measured at given conditions (e.g., temperature, pressure, and bath gas). In this equation, $N$ is the number of measurement series and $N_{i}$ is the number of data points in the $i$ th measurement series. The value $y_{i j}^{\exp }$ is the $j$ th data point in the $i$ th measurement series. The corresponding modeled value $y_{i j}^{\bmod }(\mathbf{p})$ belonging to parameter set $\mathbf{p}$ can be obtained by calculating the rate coefficient at the given temperature (and pressure, bath gas, etc.), or by carrying out a simulation with chemical kinetic codes using an appropriate detailed mechanism. The importance of the $i$ th measurement series can be changed by using individual weight $w_{\mathrm{i}}$. In this work, unit weights were used.

The objective function can be transformed into a simpler form by introducing a single index $k$, which runs through all data points of all measurement series. A new unified weight $\mu_{k}=\mathrm{w}_{\mathrm{k}} / N_{k}$ is used for each data point, which further simplifies the objective function:

$$
E(\mathbf{p})=\sum_{k=1}^{N} \mu_{k}\left(\frac{Y_{k}^{\bmod }(\mathbf{p})-Y_{k}^{\exp }}{\sigma\left(Y_{k}^{\exp }\right)}\right)^{2}
$$

This equation can be condensed by introducing matrix-vector notation:

$$
E(\mathbf{p})=\left(\mathbf{Y}_{\bmod }(\mathbf{p})-\mathbf{Y}_{\exp }\right)^{\mathrm{T}} \mathbf{W} \Sigma_{\mathbf{Y}}^{-1}\left(\mathbf{Y}_{\bmod }(\mathbf{p})-\mathbf{Y}_{\exp }\right) .
$$

Matrices $\mathbf{W}$ and $\boldsymbol{\Sigma}_{\mathbf{Y}}$ are the diagonal matrices of weights $\mu_{k}$ and variances $\sigma^{2}\left(Y_{i j}^{\exp }\right)$, respectively. The covariance matrix of the fitted parameters $\boldsymbol{\Sigma}_{\mathbf{p}}$ was estimated [2] using the following equation:

$$
\begin{aligned}
\Sigma_{\mathbf{p}}= & {\left[\left(\mathbf{J}_{\mathrm{o}}^{\mathrm{T}} \mathbf{W} \Sigma_{\mathbf{Y}}^{-1} \mathbf{J}_{\mathrm{o}}\right)^{-1} \mathbf{J}_{\mathrm{o}}^{\mathrm{T}} \mathbf{W} \Sigma_{\mathbf{Y}}^{-1}\right] } \\
& \times\left(\Sigma_{\mathbf{Y}}+\Sigma_{\Delta}\right)\left[\left(\mathbf{J}_{\mathrm{o}}^{\mathrm{T}} \mathbf{W} \Sigma_{\mathbf{Y}}^{-1} \mathbf{J}_{\mathrm{o}}\right)^{-1} \mathbf{J}_{\mathrm{o}}^{\mathrm{T}} \mathbf{W} \Sigma_{\mathbf{Y}}^{-1}\right]^{\mathrm{T}}
\end{aligned}
$$

where $\Sigma_{\Delta} \approx \Delta \mathbf{Y} \Delta \mathbf{Y}^{\mathrm{T}}, \Delta \mathbf{Y} \approx \overline{\mathbf{Y}}_{\text {mod }}-\mathbf{Y}_{\text {exp }}$. Matrix $\mathbf{J}_{\mathbf{0}}$ is the derivative matrix of $\mathbf{Y}_{\text {mod }}$ with respect to $\mathbf{p}$ at the optimum.

The diagonal elements of matrix $\boldsymbol{\Sigma}_{\mathbf{p}}$ are the variances of parameters $\sigma^{2}\left(p_{i}\right)$. The off-diagonal elements are covariances $\operatorname{cov}\left(p_{i}, p_{j}\right)=r_{p_{i}, p_{j}} \sigma_{p_{i}} \sigma_{p_{j}}$; therefore, the correlation coefficients $r_{p_{i}, p_{j}}$ can be calculated from the off-diagonal element and the standard deviations:

$$
r_{p i, p j}=\frac{\left(\Sigma_{\mathbf{p}}\right)_{i, j}}{\sigma_{p i} \sigma_{p j}}
$$

Covariances of the logarithm of the rate coefficients at temperature $T$ can be calculated in the following way:

$$
\operatorname{cov}\left(\ln k_{i}(T), \ln k_{j}(T)\right)=\Theta^{\mathrm{T}} \Sigma_{\mathbf{p}_{i}, \mathbf{p}_{j}} \Theta
$$

Here $\Theta=\left(1, \ln \{T\},-\mathrm{T}^{-1}\right)^{T}, \mathbf{p}_{i}=\left(\ln A_{i}, n_{i}, \mathrm{E}_{\mathrm{i}} / R\right)^{\mathrm{T}}$, and $\Sigma_{\mathbf{p}_{i}, \mathbf{p}_{j}}$ denotes a block of matrix $\boldsymbol{\Sigma}_{\mathbf{p}}$ that contains 
Table II Objective Function Values E(p) Obtained with the Initial and the Optimized Models

\begin{tabular}{lcc}
\hline & Original Model & Optimized Model \\
\hline Objective function value $E$ & 5.07 & 3.57 \\
Sum of partial objective function values $E_{i}$ belonging to the H-ARAS measurements & 3.54 & 2.35 \\
Sum of partial objective function values $E_{i}$ belonging to the I-ARAS measurements & 1.17 & 1.14 \\
Sum of partial objective function value $E_{i}$ belonging to the Michael et al. and the & 0.36 & 0.08 \\
$\quad$ Vasileiadis and Benson measurements & & \\
\hline
\end{tabular}

the covariances of the Arrhenius parameters of reactions $i$ and $j$. This equation provides variance $\sigma^{2}\left(\ln k_{\mathrm{i}}(T)\right)$ if $i=j$.

In high-temperature gas kinetics, the uncertainty of the rate coefficient at given temperature $T$ is usually defined by uncertainty parameter $f$ (see, e.g., [8]) in the following way:

$$
\begin{aligned}
f(T) & =\log _{10}\left(k^{0}(T) / k^{\min }(T)\right) \\
& =\log _{10}\left(k^{\max }(T) / k^{0}(T)\right)
\end{aligned}
$$

where $k^{0}$ is the recommended value of the rate coefficient and values below $k^{\text {min }}$ and above $k^{\text {max }}$ are considered to be very improbable. Assuming that the minimum and maximum values of the rate coefficients corresponds to $3 \sigma$ deviations from the recommended values on a logarithmic scale, uncertainty $f$ can be obtained [18] at a given temperature $T$ from the standard deviation of the logarithm of the rate coefficient using the following equation:

$$
f(T)=3 \sigma\left(\log _{10} k\right)=\frac{3}{\ln 10} \sigma(\ln k)
$$

The optimization of the model for the pyrolysis of ethyl iodide was based on 29 ARAS measurements, the measured rate coefficient of reaction (R4) by Vasileiadis and Benson [13] and the 13 measured rate coefficients for the reverse reaction of (R4) from Michael et al. [11]. We assumed that the measured hydrogen and iodine concentrations have absolute errors $\left(\sigma\left(y_{i j}^{\exp }\right) \approx\right.$ constant $)$, and the measured rate coefficients have relative errors $\left(\sigma\left(\ln k^{\exp }\right) \approx\right.$ constant $)$. The assumed standard deviations of the concentration measurements are listed in Table 1 of the Supporting Information and were deduced from the scatter of the data points at linear sections of the curves occurring at longer timescales. The rate coefficient measurements of Michael et al. [11] were assigned a relative uncertainty of $13.5 \%$, which corresponds to a standard deviation of $\sigma\left(\ln k^{\exp }\right)=0.135$. This standard deviation was deduced from the scatter of the measured rate coefficients. The rate coefficient measured by Vasileiadis and Benson [13] was assigned an uncertainty of $10 \%$ based on the authors' estimation.

Initially 5000 Arrhenius parameter sets were generated within their range of uncertainty, the parameter set giving the lower objective function was selected, and the range of uncertainty of the determined Arrhenius parameters was calculated using statistical methods [2]. Next, 500 parameter sets were selected within this narrower uncertainty region, and the procedure was repeated until the value of the objective function decreased negligibly. Starting from this point, a local minimum search was carried out using the fminsearch function of MATLAB. Note that the optimum identified by this local search was very close to the minimum found by the global minimization process. The objective function values belonging to the initial and the optimized models are given in Table II. Owing to the optimization, the description of the ARAS measurements significantly improved, and the rate coefficient measurements from [11] could also be well described. Figures $2 \mathrm{a}$ and $2 \mathrm{~b}$ show two typical measurements and their simulation with the original and optimized model. Table I shows the original and optimized values of the Arrhenius parameters.

Figure 3 shows that the optimized rate coefficients are within their a priori determined uncertainty ranges in temperature range 950-1400 $\mathrm{K}$ and could be determined with high accuracy. Figure 4 compares our results with the rate coefficient expressions previously published in the literature for reactions (R1) and (R3)(R5). These figures include data from both experimental and theoretical works. Some data were originally obtained for the rate coefficient of the reverse reaction, and these data were transformed to the forward rate coefficient using the thermodynamic data. For reactions (R1) and (R3), the data of Yang and Tranter [19] correspond to their rate coefficient expression extrapolated to infinite pressure (see the rate expression at the bottom of p. 439 in [19]). Yang and Tranter [19] determined the sum of the rate coefficients of reactions (R1) and (R3) in the temperature range of 1150-1870 $\mathrm{K}$ and calculated the individual (R1) and (R3) rate coefficients using a temperature independent branching 

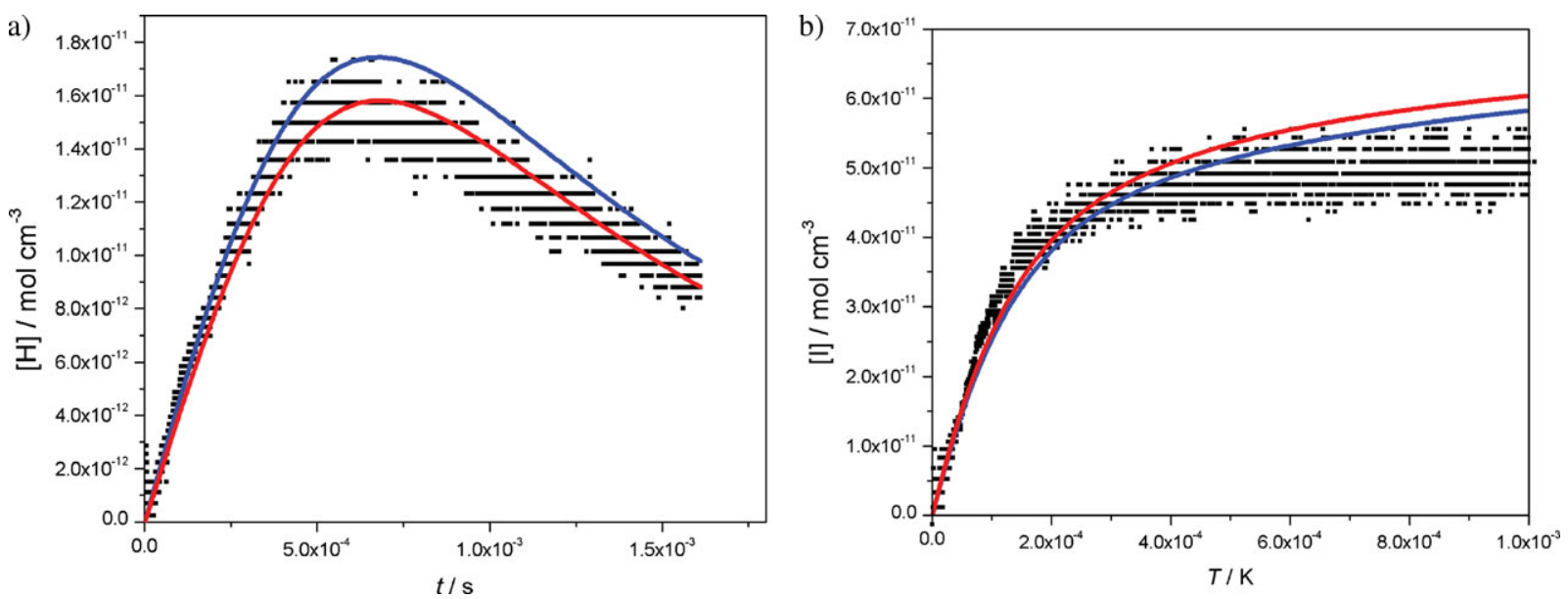

Figure 2 Experimental data of two ARAS measurements and the corresponding simulation results. Black dots: measured values, blue line: original model, red line: optimized model. Experimental conditions for H-ARAS measurement (left plot): $T=973 \mathrm{~K}, p=1.7$ bar, $c_{0}\left(\mathrm{C}_{2} \mathrm{H}_{5} \mathrm{I}\right)=1.1 \times 10^{-10} \mathrm{~mol} \mathrm{~cm}^{-3}$. Experimental conditions for the I-ARAS measurement (right plot): $T=1084 \mathrm{~K}, p=1.7$ bar, $c_{0}\left(\mathrm{C}_{2} \mathrm{H}_{5} \mathrm{I}\right)=6.5 \times 10^{-11} \mathrm{~mol} \mathrm{~cm}^{-3}$.

ratio of 0.87 , which had been suggested by Kumaran et al. [20]

For reaction (R5), our uncertainty region has an hourglass shape, which means that our rate coefficient has low uncertainty near $1000 \mathrm{~K}$ and rapidly increasing uncertainty toward both higher and lower temperatures. The reason is that the simulations of the H-ARAS measurements are most sensitive to the rate coefficient of $\mathrm{R} 5\left(\mathrm{C}_{2} \mathrm{H}_{5} \mathrm{I}+\mathrm{H} \rightarrow \mathrm{C}_{2} \mathrm{H}_{5}+\mathrm{HI}\right)$ at about $1000 \mathrm{~K}$. The I-ARAS measurements were performed only above $1050 \mathrm{~K}$ and are less influenced by (R5). This reaction mostly affects the longer timescale decrease of the $\mathrm{H}$ concentration, which was not inspected in the higher temperature measurements. Also, at temperatures lower than $1000 \mathrm{~K}$, the effect of reaction (R4) $\left(\mathrm{H}+\mathrm{HI} \rightarrow \mathrm{H}_{2}+\mathrm{I}\right)$ becomes comparable to (R5) in the $\mathrm{H}$ atom consumption and, therefore, the influence of (R5) is smaller at low temperatures.

The rate expression for reaction (R5) suggested by Yang and Tranter (see Table I in [19]) is mostly within our uncertainty bounds. Note that these Arrhenius parameters were fitted to their experimental data, but this rate coefficient was influential only in the first $2 \mu$ s of their experimental curves (see the comment on p. 441 in [19]). Yuan et al. [21] also measured the rate coefficient of reaction (R5), but in a different temperature region (295-624 K). Westbrook and Dryer [22] provided an estimation of the Arrhenius parameters of (R5), but it was not included in Fig. 4 as these values are without experimental background.

Figure 5 shows the $\mathrm{C}_{2} \mathrm{H}_{5} \mathrm{I}$ decomposition branching ratio, $k_{\mathrm{R} 1} /\left(k_{\mathrm{R} 1}+k_{\mathrm{R} 3}\right)$, from our optimized rate parameters. This branching ratio is 0.936 at $900 \mathrm{~K}$, decreasing nearly linearly to 0.834 at $1400 \mathrm{~K}$. The ex- trapolated branching ratio is 0.738 at $2000 \mathrm{~K}$. Kumaran et al. [20] suggested a branching ratio of $0.87 \pm 0.11$ for the temperature range 950-2050 K. Yang and Tranter [19] accepted this ratio but noted that their experimental data could also be reproduced with any branching ratio higher than 0.87 (cf. the caption of Fig. 3 in [19]). Miyoshi et al. [23] carried out shock tube experiments coupled to I-ARAS detection in the temperature range of 950-1400 $\mathrm{K}$ and found a branching ratio of $0.92 \pm 0.06$. Weber et al. [24] investigated the thermal decomposition of $\mathrm{C}_{2} \mathrm{H}_{5} \mathrm{I}$ in the temperature range $770-1200 \mathrm{~K}$ with flash pyrolysis and product detection by photoionization mass spectrometry. They determined a branching ratio of $0.7 \pm 0.1$. This means that the branching ratio obtained from our optimized rate coefficients is in good accordance with most previous measurements. Note that these experimental data belong to different pressure ranges indicated in the caption of Fig. 5; this also has to be taken into consideration in the comparison of the measured branching ratios.

An advantage of our approach is that the relation of the fitted parameters is also characterized. The joint covariance matrix of the optimized Arrhenius parameters was calculated, and it can be used to obtain both the $f(T)$ uncertainty functions and the correlation coefficients between pairs of rate coefficients. The covariance and correlation matrices are given in Tables 2 and 3, respectively, in the Supporting Information.

The $f(T)$ functions are shown in Fig. 6. These uncertainty parameters correspond to the following $1 \sigma$ uncertainties of the rate coefficients: $2 \%-3 \%$ for reaction (R1), $6 \%$ for reaction (R4), $15 \%-25 \%$ for reaction (R3), and $5 \%-40 \%$ for reaction (R5). 
a) Reaction R1

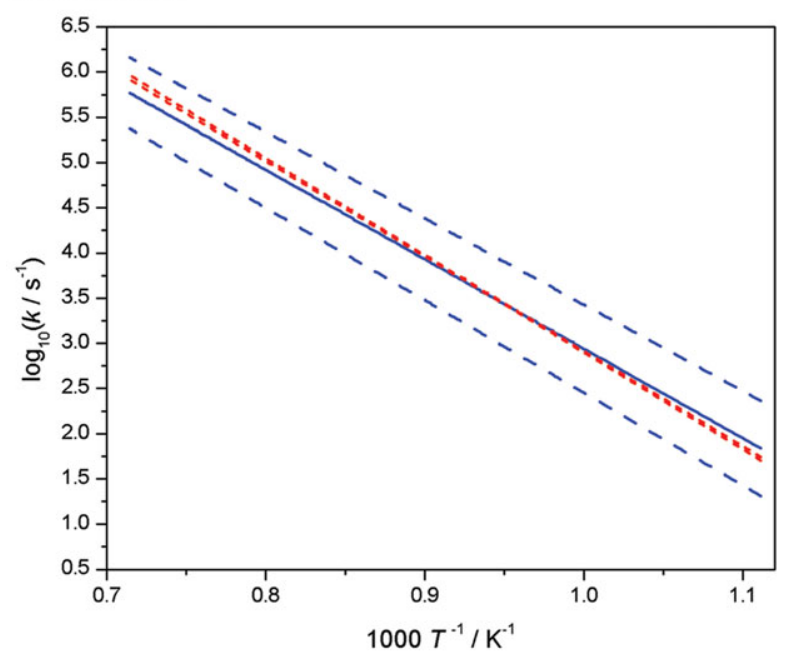

c) Reaction R4

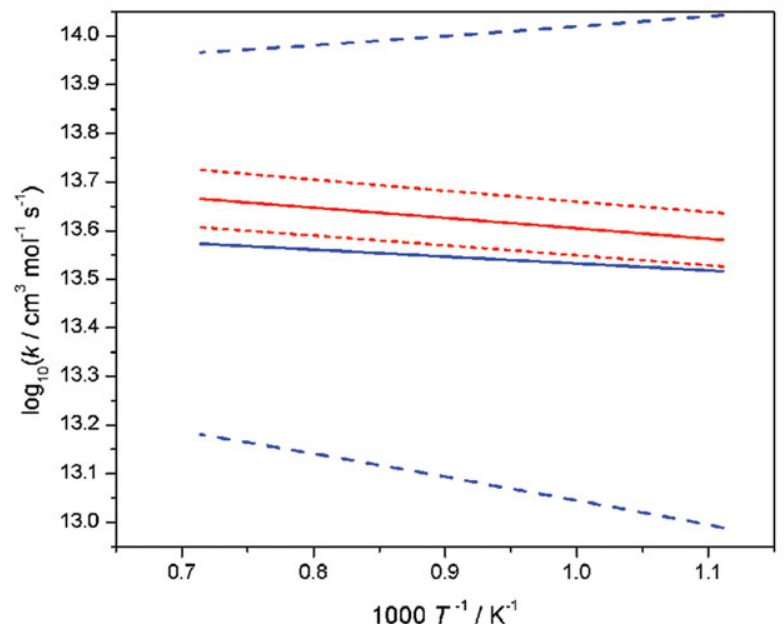

b) Reaction R3

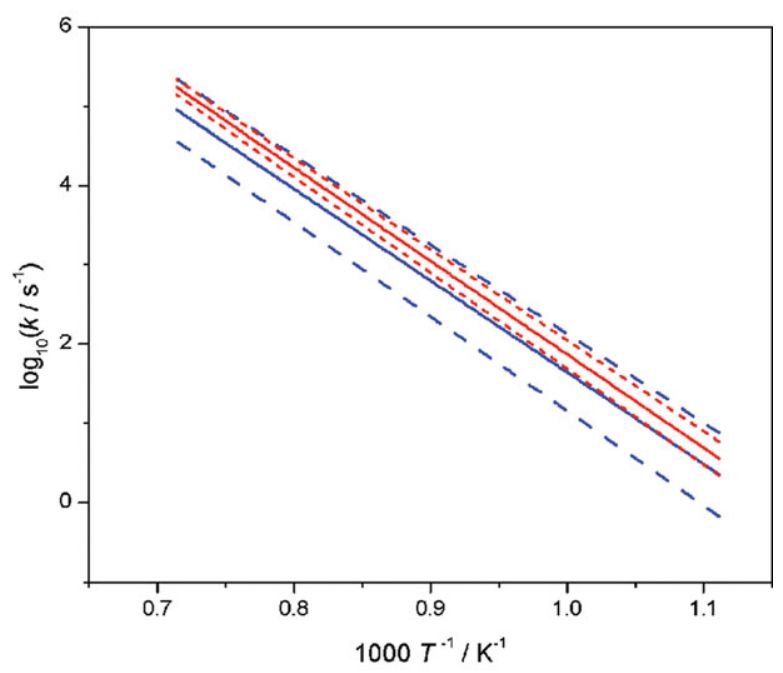

d) Reaction R5

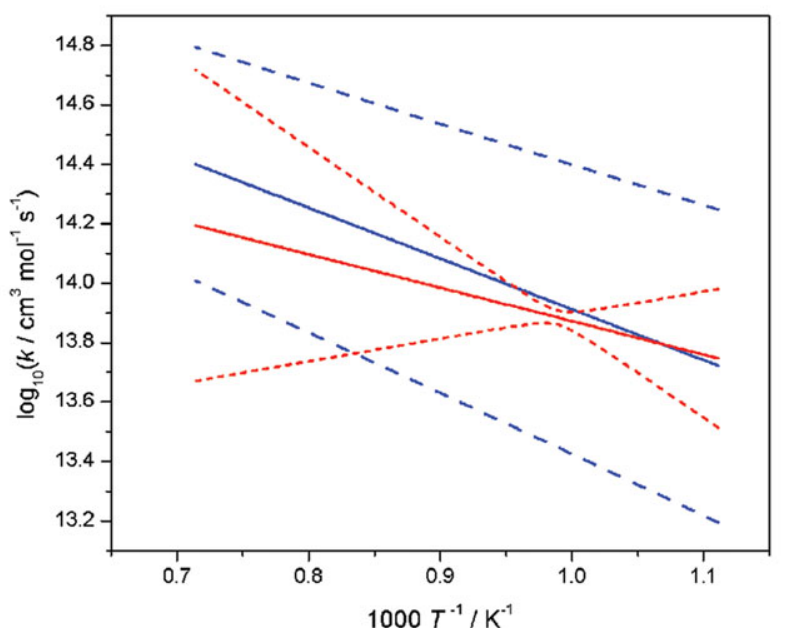

Figure 3 Arrhenius plot of the rate coefficient expressions for reactions (R1) and (R3)-(R5) in the temperature range of 900$1400 \mathrm{~K}$. The initial values and their uncertainty range are plotted with solid and dashed blue lines, respectively. The optimized values and uncertainty ranges are plotted with solid and short dashed red lines, respectively.

The correlation coefficients of the rate coefficient pairs are shown in Fig. 7. Several of the correlation coefficients have an absolute value close to unity at a wide range of temperatures. The reason is that the $\mathrm{H}$ and I atom concentration profiles can be simulated similarly with different parameter sets. It is a challenge to provide an explanation for the temperature dependence of the correlation coefficients because they are determined from the H-ARAS and I-ARAS experiments and the measured rate coefficient values. The rate coefficient of each reaction step has a different effect on the simulation results related to the different types of measurements.

\section{SUMMARY}

The optimization of a kinetic model of the pyrolysis of ethyl iodide was carried out on the basis of reflected shock wave experiments with H-ARAS and I-ARAS detection [1], and rate coefficient measurements from Michael et al. [11], and Vasileiadis and Benson [13]. Arrhenius parameters $A$ and $E$ of the following four reactions were determined in the temperature range 950-1400 $\mathrm{K}$ and a pressure range of 1-2 bar: (R1): $\mathrm{C}_{2} \mathrm{H}_{5} \mathrm{I} \rightarrow \mathrm{C}_{2} \mathrm{H}_{5}+\mathrm{I}$; (R3): $\mathrm{C}_{2} \mathrm{H}_{5} \mathrm{I} \rightarrow \mathrm{C}_{2} \mathrm{H}_{4}+\mathrm{HI}$; (R4): $\mathrm{H}+\mathrm{HI} \rightarrow \mathrm{H}_{2}+$ I; (R5): $\mathrm{C}_{2} \mathrm{H}_{5} \mathrm{I}+\mathrm{H} \rightarrow \mathrm{C}_{2} \mathrm{H}_{5}+$ $\mathrm{HI}$. The simulation results obtained with the optimized 
a) Reaction R1

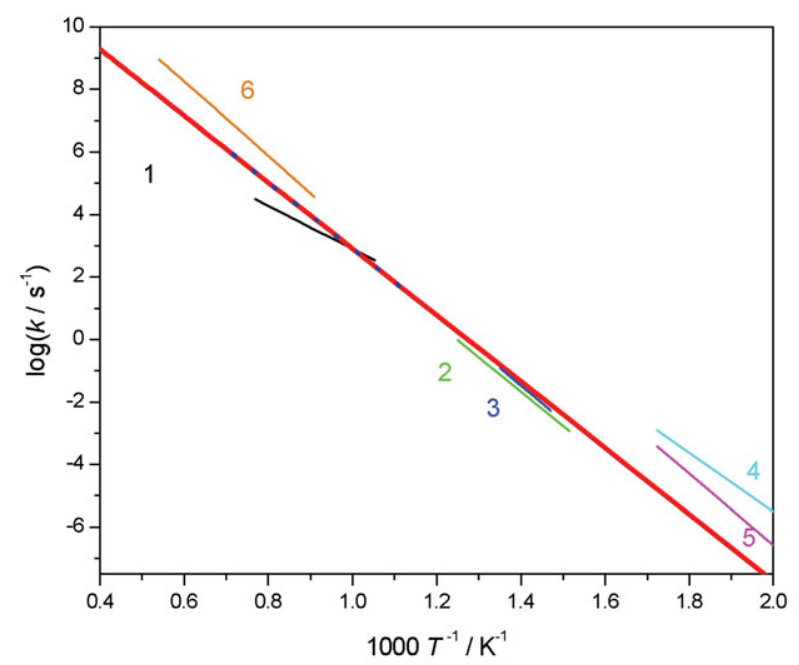

c) Reaction R4

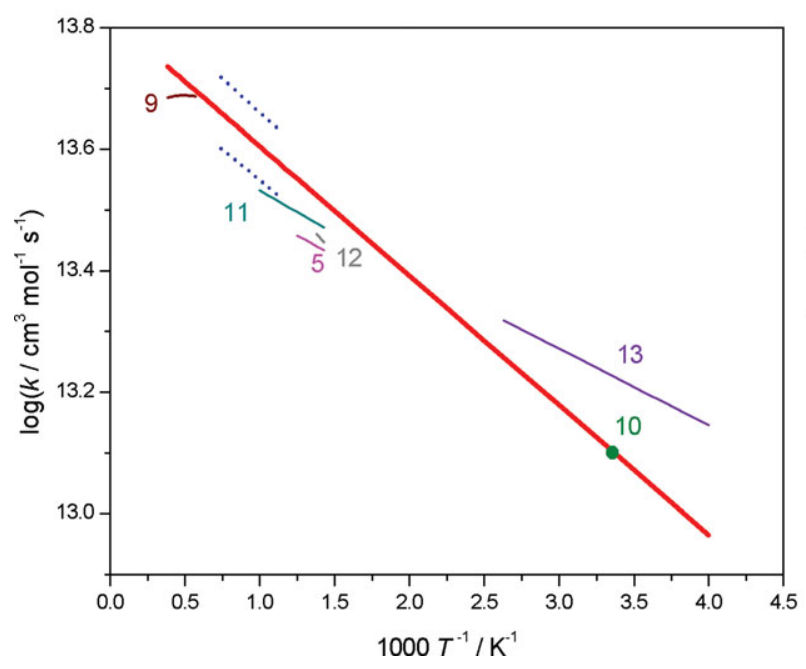

b) Reaction R3

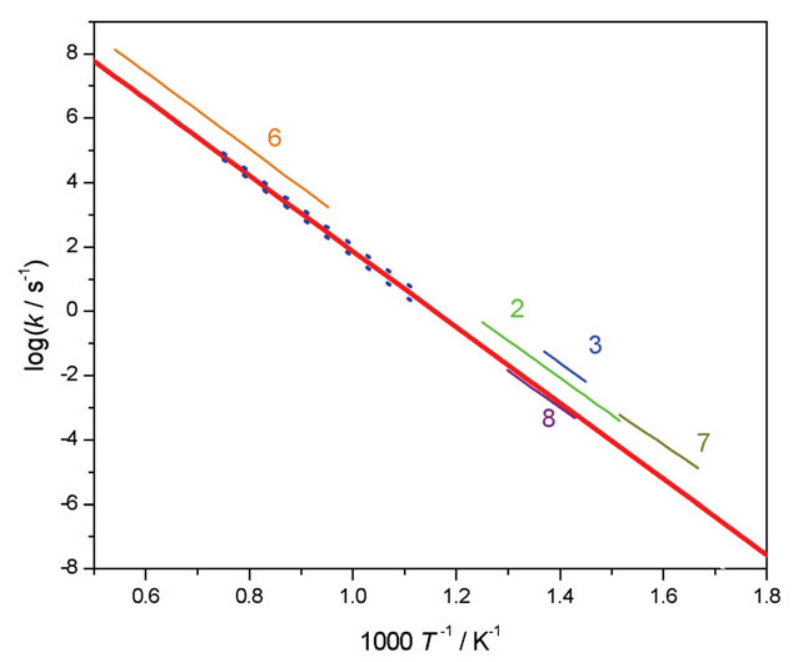

d) Reaction R5

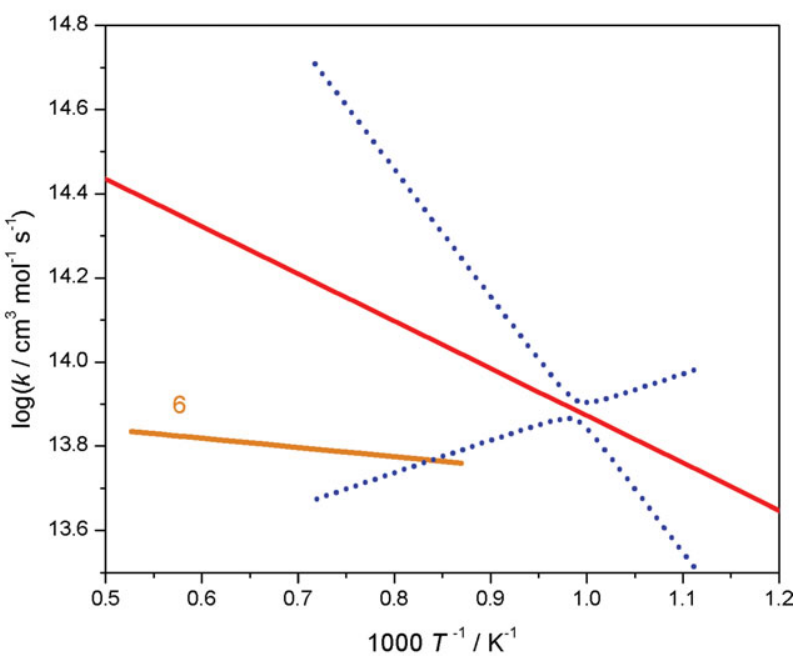

Figure 4 Arrhenius plot for reactions (R1) and (R3)-(R5). The rate coefficient expressions determined in this work are plotted with thick red lines, and the corresponding uncertainty limits are given with blue dotted lines. The uncertainty limits are indicated only in the temperature range of our measurements $(950-1400 \mathrm{~K})$. The numbered thin lines show previously published rate coefficients: (1) Kumaran et al. [20] ( $p=0.1-0.7$ bar), (2) Yang and Conway [25] ( $p=0.02$ bar), (3) Shilov and Sabirova [26], (4) Ogg [27] ( $p=0.2$ bar), (5) Sullivan [17] ( $p=0.2$ bar), (6) Yang and Tranter [19] ( $p=0.07-0.16$ bar; plotted values are the high-pressure extrapolation), (7) Benson and Bose [28] ( $p=0.08-0.25$ bar), (8) Butler and Polanyi [29] ( $p=0.002-0.017$ bar), (9) Michael et al. [11], (10) Vasileiadis and Benson [13], (11) Baulch et al. [9], (12) Lorenz et al. [16], (13) Sullivan [30], and (14) Yuan et al. [21]

Arrhenius parameters showed a significantly better agreement with the experimental results compared to the simulations performed with the initial parameters.

The joint covariance matrix of the optimized Arrhenius parameters was also determined. This covariance matrix was converted to the temperature-dependent uncertainty parameters $f$ of the rate coefficients and also to the temperature-dependent correlation coeffi- cients between pairs of rate coefficients. Each fitted rate coefficient was determined with higher accuracy compared to the data previously available in the literature.

The procedure used here is applicable to the interpretation of other shock tube experiments as well. In most current approaches, the rate coefficients found in the literature are either used as fixed values in a reaction mechanism or considered as initial values only and are 


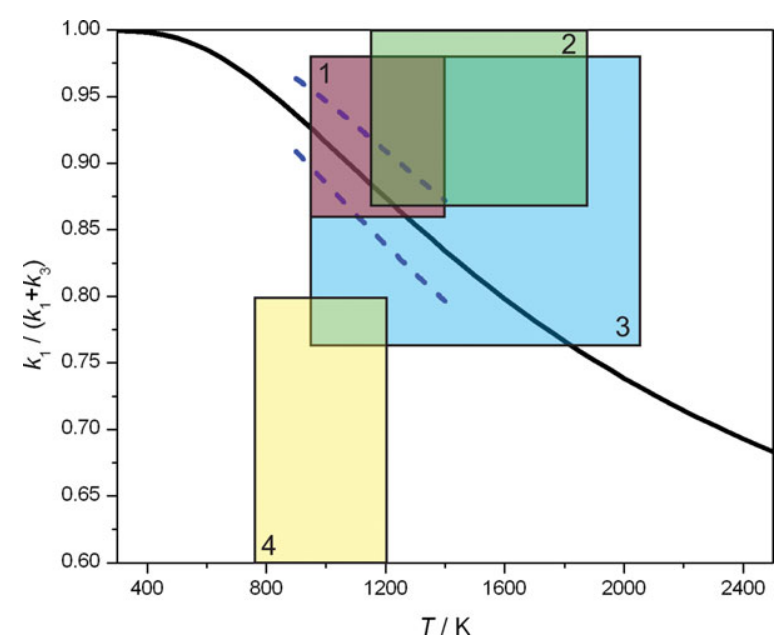

Figure 5 Branching ratio of the $\mathrm{C}_{2} \mathrm{H}_{5} \mathrm{I} \rightarrow \mathrm{C}_{2} \mathrm{H}_{5}+\mathrm{I}$ (R1) and $\mathrm{C}_{2} \mathrm{H}_{5} \mathrm{I} \rightarrow \mathrm{C}_{2} \mathrm{H}_{4}+\mathrm{HI}$ (R3) reactions, based on the optimized values of the rate coefficients. The dashed lines show the $3 \sigma$ uncertainty limits. The shaded areas show the uncertainty ranges of the reported branching ratios in the corresponding temperature region: (1) $0.92 \pm$ 0.06 , Miyoshi et al. [23] ( $p=0.6-1.9$ bar); (2) higher than 0.87, Yang and Tranter [19] ( $p=0.07-0.16$ bar); (3) $0.87 \pm 0.11$, Kumaran et al. [20] ( $p=0.1-0.7$ bar $)$; and (4) $0.7 \pm 0.1$, Weber et al. [24] ( $p=1.5$ bar).

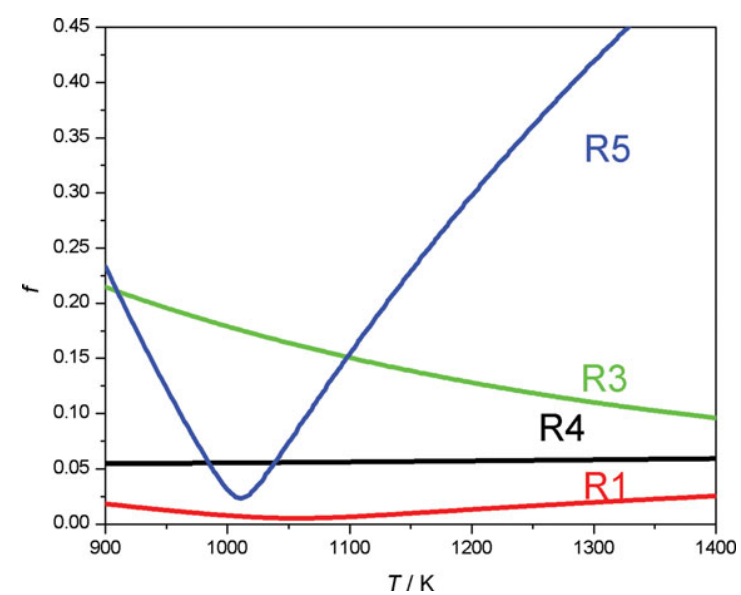

Figure 6 Temperature-dependent $f$ uncertainty functions for the four optimized rate coefficients.

completely overridden during the fitting. The method used here may consider all previously published rate coefficients together with their uncertainty. In this way, the own experimental data can be used together with the experimental data previously published by other researchers, and thus the deduced kinetic mechanism can be established with a higher reliability.
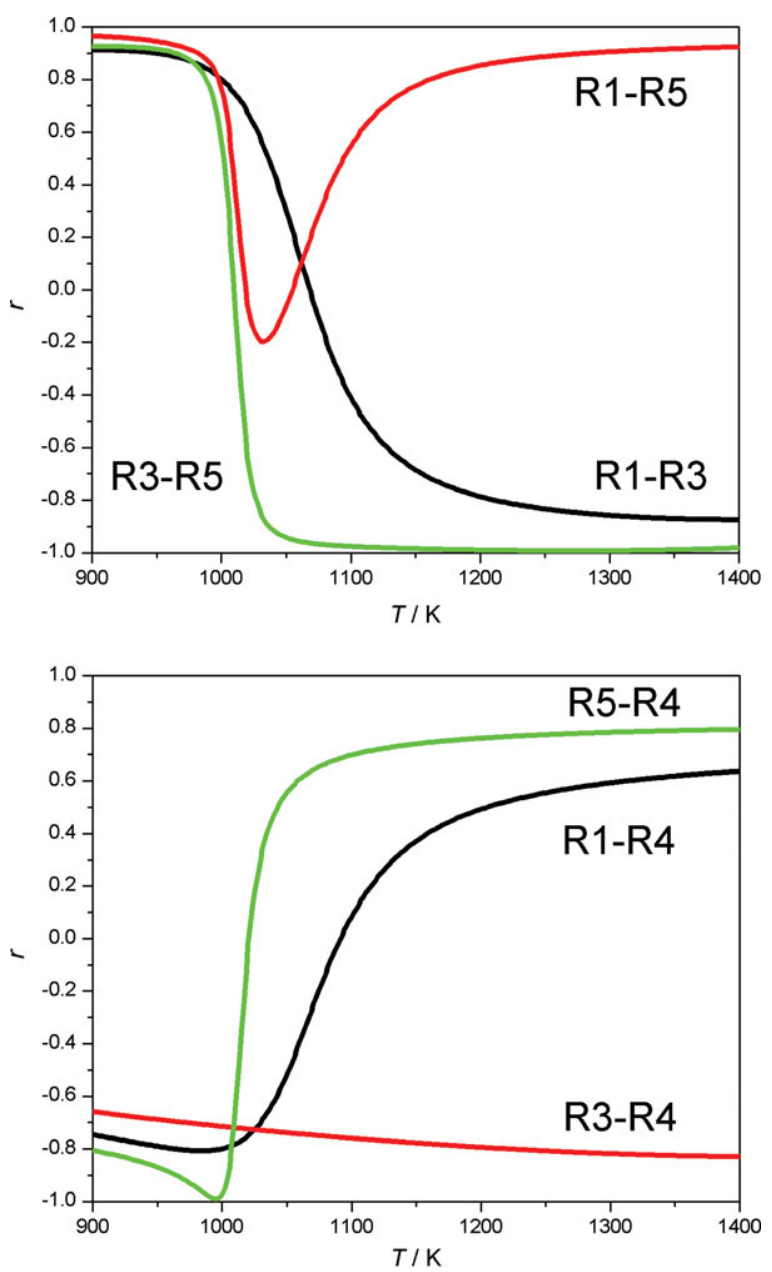

Figure 7 Correlation coefficients of the optimized rate coefficient pairs.

The authors thank Dr. Tibor Nagy for his important suggestions and Ms. Éva Valkó for the determination of the uncertainty limits of the rate parameters of reaction (R4). We also would like to thank Dr. Philipp Friese for the technical processing of the ARAS data files. This work was done within collaboration COST Action CM0901: Detailed Chemical Kinetic Models for Cleaner Combustion, and it was partially financed by OTKA grant K84054.

\section{BIBLIOGRAPHY}

1. Bentz, T.; Szori, M.; Viskolcz, B.; Olzmann, M. Z. Phys Chem 2011, 225, 1117-1128.

2. Turányi, T.; Nagy, T.; Zsély, I. G.; Cserháti, M.; Varga, T.; Szabó, B. T.; Sedyó, I.; Kiss, P. T.; Zempléni, A.; Curran, H. J. Int J Chem Kinet 2012, 44, 284-302.

3. Zsély, I. G.; Varga, T.; Nagy, T.; Cserháti, M.; Turányi, T.; Peukert, S.; Braun-Unkhoff, M.; Naumann, C.; Riedel, U. Energy 2012, 43, 85-93. 
4. Appel, D.; Appleton, J. P. Proc Combust Inst 1975, 15, 701-715.

5. Fernandes, R. X.; Giri, B. R.; Hippler, H.; Kachiani, C.; Striebel, F. J Phys Chem A 2005, 109, 1063-1070.

6. Just, T. In Shock Waves in Chemistry; Lifshitz, A., Ed.; Marcel Dekker: New York, 1981; pp. 279-318.

7. Kumaran, S. S.; Su, M. C.; Michael, J. V. Int J Chem Kinet 1997, 29, 535-543.

8. Baulch, D. L.; Bowman, C. T.; Cobos, C. J.; Cox, R. A.; Just, T.; Kerr, J. A.; Pilling, M. J.; Stocker, D.; Troe, J.; Tsang, W.; Walker, R. W.; Warnatz, J. J Phys Chem Ref Data 2005, 34, 757-1397.

9. Baulch, D. L.; Duxbury, J.; Grant, S. J.; Montague, D. C. J Phys Chem Ref Data 1981, 10, 1-721.

10. Frenklach, M. PrIMe Database. Available at http:// www.primekinetics.org/. Accessed September 1, 2013.

11. Michael, J. V.; Kumaran, S.; Su, M. C.; Lim, K. P. Chem Phys Lett 2000, 319, 99-106.

12. MECHMOD. Available at http://garfield.chem.elte.hu/ Combustion/mechmod.htm. Accessed September 1, 2013.

13. Vasileiadis, S.; Benson, S. W. Int J Chem Kinet 1997, 29, 915-925.

14. Nagy, T.; Turányi, T. Int J Chem Kinet 2011, 43, 359378.

15. Manion, J. A.; Huie, R. E.; Levin, R. D.; Burgess, D. R., Jr.; Orkin, V. L.; Tsang, W.; McGivern, W. S.; Hudgens, J. W.; Knyazev, V. D.; Atkinson, D. B.; Chai, E.; Tereza, A. M.; Lin, C. Y.; Allison, T. C.; Mallard, W. G.; Westley, F.; Herron, J. T.; Hampson, R. F.; Frizzell, D. H. NIST
Chemical Kinetics Database, NIST Standard Reference Database 17, Version 7.0 (Web Version), Release 1.6.7 Data Version 2013.03, National Institute of Standards and Technology: Gaithersburg, MD. Available at http://kinetics.nist.gov/. Accessed September 1, 2013.

16. Lorenz, K.; Wagner, H. G.; Zellner, R. Ber Bunsen-Ges Phys Chem Chem Phys 1979, 83, 556-560.

17. Sullivan, J. H. J Chem Phys 1962, 36, 1925.

18. Turányi, T.; Zalotai, L.; Dóbé, S.; Bérces, T. Phys Chem Chem Phys 2002, 4, 2568-2578.

19. Yang, X.; Tranter, R. S. Int J Chem Kinet 2012, 44, 433-443.

20. Kumaran, S. S.; Su, M. C.; Lim, K. P.; Michael, J. V. Proc Combust Inst 1996, 26, 605-611.

21. Yuan, J.; Wells, L.; Marshall, P. J. Phys-Chem A 1997 , 101, 3542-3546.

22. Westbrook, C. K.; Dryer, F. L. Prog Energy Combust Sci 1984, 10, 1-57.

23. Miyoshi, A.; Yamauchi, N.; Kosaka, K.; Koshi, M.; Matsui, H. J Phys Chem A 1999, 103, 46-53.

24. Weber, K. H.; Lemieux, J. M.; Zhang, J. J Phys Chem A 2009, 113, 583-591.

25. Yang, J. H.; Conway, D. C. J Chem Phys 1965, 43, 1296.

26. Shilov, A. E.; Sabirova, R. D. Kinet Catal 1964, 5, 3239.

27. Ogg, R. A. J Am Chem Soc 1934, 56, 526-536.

28. Benson, S. W.; Bose, A. N. J Chem Phys 1962, 37, 2935.

29. Butler, E. T.; Polanyi, M. Trans Farad Soc 1943, 39, 19-35.

30. Sullivan, J. H. J Chem Phys 1959, 30, 1292-1300. 